\title{
C-banding in maize II. Identification of somatic chromosomes
}

\author{
Margarida L. R. de Aguiar-Perecin* \\ and Canio G. Vosa $†$
}

\author{
* Departmento de Genética, Escola Superior de \\ Agricultura “Luiz de Queiroz", Universidade de Saõ \\ Paulo, Piracicaba, S.P., Brazil; \\ $\dagger$ Botany School, University of Oxford, \\ Oxford, England
}

\begin{abstract}
A biometrical analysis of C-banded and Feulgen stained somatic metaphases of maize stocks with different knob constitutions has shown that large bands alter arm lengths of mitotic chromosomes. A representative diagram of the knobless maize somatic karyotype and of a high knobbed stock are presented.
\end{abstract}

\section{INTRODUCTION}

The identification of maize chromosomes according to their relative length, centromere position, knobs and prominent chromomeres, determined from pachytene studies (Rhoades, 1950; Neuffer et al., 1968; McClintock, 1978) is now well standardised and generally accepted.

Chen (1969) and Filion and Walden (1973), showed that maize somatic chromosomes can be identified according to their relative length and arm ratio in Feulgen stained metaphases.

C-banded somatic metaphases have revealed the presence of distal bands, that correspond with knobs (Vosa and Aguiar, 1972; Hadlaczky and Kálmán, 1975; Sachan and Tanaka, 1977; Ward, 1980; Aguiar-Perecin, in press), but no diagrammatic representation of the band positions on the chromosomes has ever been made.

In the present study, a biometrical analysis of C-banded karyotypes of maize stocks with different knob constitutions has shown that large bands alter arm lengths of mitotic chromosomes. A representative diagram of a highly knobbed stock and of a knobless one are presented.

\section{MATERIALS AND METHODS}

Inbred stocks of which C-banded karyotypes have been previously described (Aguiar-Perecin, in press) and derived from populations of the
Table 1 Designation and knob constitution of maize stocks

\begin{tabular}{ll}
\hline Stocks & Racial origin and knob constitution* \\
\hline $371 \mathrm{~A}-4$ & $\begin{array}{l}\text { Ceremonial, heterozygous for knobs at } 2 L \\
\text { (medium size) and } 7 L \text { (small size). }\end{array}$ \\
12 & $\begin{array}{l}\text { Ceremonial, with medium size knobs at } 2 L \text { and } \\
5 L \text { and small ones at } 6 L_{2}, 6 L_{3}, 7 L \text { and } 8 L .\end{array}$ \\
18 & $\begin{array}{l}\text { Zapalote Chico, homozygous for large and } \\
\text { medium sized knobs at } 1 S, 2 S, 2 L, 3 S, 3 L, 4 S, \\
\end{array}$ \\
& $4 L, 5 S, 5 L, 6 L_{2}, 6 L_{3}, 7 S, 7 L, 8 L_{1}, 8 L_{2}, 9 S$. \\
\hline
\end{tabular}

* Knobs $6 L_{2}, 6 L_{3}, 8 L_{1}$ and $8 L_{2}$ are telescoped together at mitotic metaphase and are represented as single bands in the ideograms of fig. 3 .

Brazilian Ceremonial maize (Avati-Moroti racial group, according to Brieger et al., 1958) and the Mexican race Zapalote Chico were used (table 1).

Measurements of the chromosome arm lengths and the relative positions of $\mathrm{C}$-bands were made in micrographs taken from C-banded and Feulgen stained metaphases. Generally, the C-banding procedure previously described by Aguiar-Perecin (in press) was used. Feulgen staining was performed according to Chen (1969), with some modifications, as follows. Excised root tips from germinating seedlings were pretreated, in 8-hydroxyquinoline, for 2 hours. After fixation in alcohol-acetic acid $(3: 1)$, they were kept in 70 per cent alcohol at $5^{\circ} \mathrm{C}$. Feulgen staining was made as follows: hydrolysis in $1 \mathrm{~N} \mathrm{HCl}$ at $60^{\circ} \mathrm{C}$ for 8 minutes, washing in distilled water, staining in leuco-basic fuchsin for 45 minutes, and washing in tap water for 
45 minutes. The roots were then transferred to 45 per cent acetic acid for 5 minutes and squashed in 1 per cent acetocarmine. The cover-slips were removed in 45 per cent acetic acid, air dried and mounted in Canada balsam.

Suitably spread metaphases were photographed on Kodak High Contrast Copy film. Arm lengths were determined from photographic prints magnified to $\times 5000$, with a pair of callipers and read off to the nearest $\times 0.5 \mathrm{~mm}$ on an amplified millimetre paper. Chromosome length estimates of each chromosome were derived by generating two chromosome indexes expressed as: (a) percentage of the haploid set length; (b) percentage of the length of chromosome 10 . This latter ratio was included because chromosome 10 had no bands in the stocks analysed, so that its length represents a fixed parameter for comparing the lengths of each chromosome of the complement. The centromere position was expressed as arm ratio values (long/short arm). For each chromosome arm, band positions were determined by calculating the distance of the band centre from the centromere. This value was expressed as the percentage of the respective chromosome arm (see Paris Conference, 1971, and also Greilhuber and Speta (1976)).
For the diagrammatic representation of each chromosome of the complement, homologous pairs with and without bands were compared through a $t$-test, with suitable modifications. The $t$-test procedure was based on a previous comparison between sample variances (according to Steel and Torie, 1960). As Feulgen stained metaphases permitted more accurate measurements of chromosome arms, only these values have been used in the present statistical analysis.

\section{RESULTS AND DISCUSSION}

The analysis of the somatic karyotypes of the stocks used in the present study, has made possible the diagrammatic representation of maize karyotype without bands and of a karyotype showing bands corresponding to large and medium size knobs in almost all the positions known to occur in maize.

In the three stocks analysed, the chromosomes could be easily identified according to their relative length and arm ratio both in Feulgen and C-banded metaphases. Figs. 1 and 2 show the C-banded karyotypes of stock 18 of Zapalote Chico and of the hybrid $18 \times 371 \mathrm{~A}-4$ respectively. In the latter

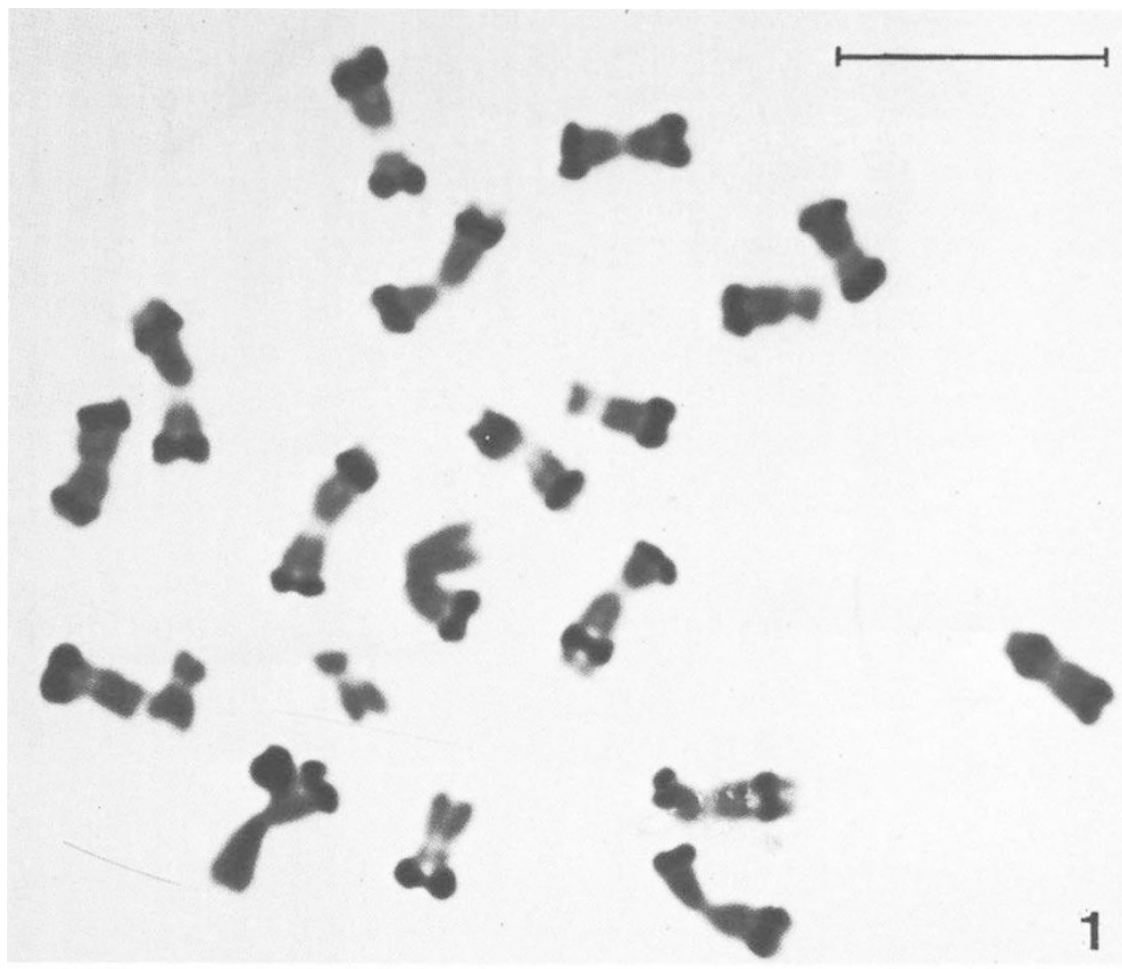

Figure 1 C-banded mitotic metaphase in stock 18 of the Zapalote Chico race. The dark stained bands correspond to knobs. Knobs at $6 L_{2}$ and $6 L_{3}$ and $8 L_{1}$ and $8 L_{2}$ in the pachytene stage appear as single bands in metaphase chromosomes. 


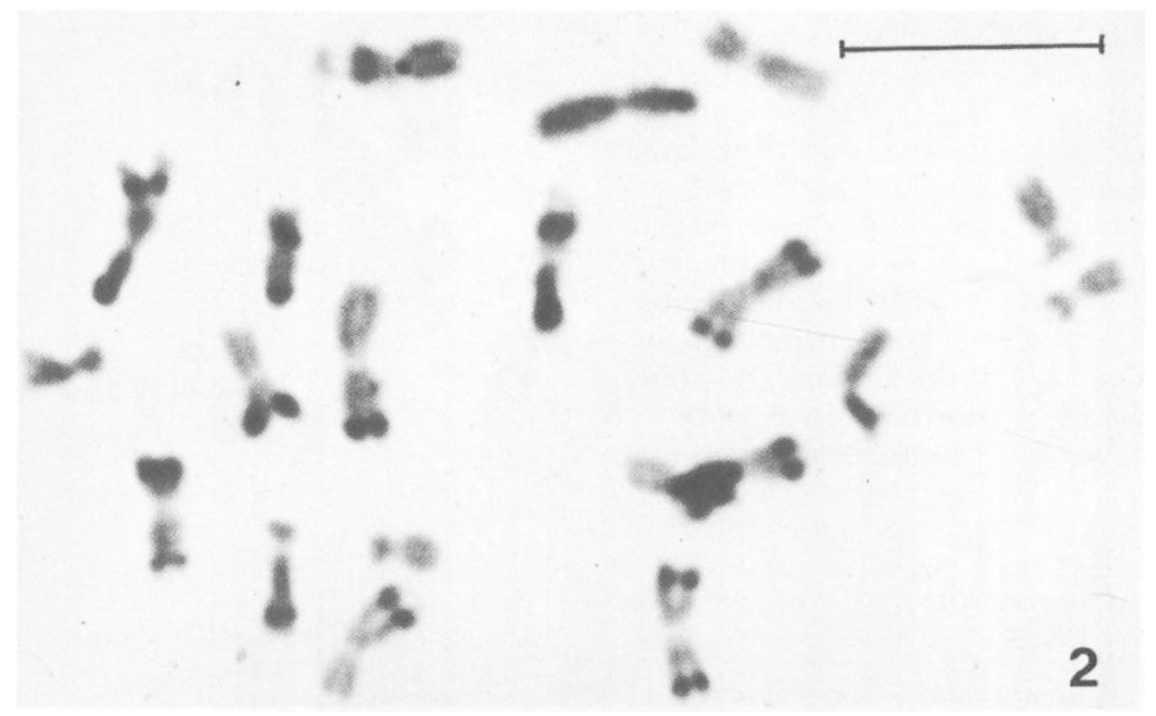

Figure 2 C-banded mitotic metaphase in the hybrid $18 \times 371 \mathrm{~A}-4$.

karyotype it may be observed that bands corresponding to large and medium sized knobs alter the length of chromosome arms of the Zapalote Chico stock, as compared with the respective chromosomes from Ceremonial maize, which has bands only in the long arms of chromosomes 2 and 7 .

No differences in the absolute length of chromosome 10 of both stocks have been found (table 2). Thus, this chromosome could be taken as "standard" for generating chromosome indices.

Table 2.) Absolute length of chromosome 10 (expressed in arbitrary units) of chromosome 10 of Zapalote Chico and Ceremonial

\begin{tabular}{lll}
$\begin{array}{l}\text { Zapalote Chico } \\
\text { (Stock 18) } \\
n=22\end{array}$ & $\begin{array}{l}\text { Ceremonial } \\
\text { (Stock 371 A-4) } \\
n=18\end{array}$ & $t$ \\
\hline $9.93 \pm 1.58$ & $9.66 \pm 0.79$ & 0.70 n.s. \\
\hline
\end{tabular}

$n=$ Number of metaphases.

Table 3 shows the values of chromosome relative lengths, expressed as a percentage of the length of chromosome 10, calculated on 22 metaphases (from 5 plants of stock 18) and 18 metaphases (from 7 plants) of stock 37lA-4 of Ceremonial maize. In stock $371 \mathrm{~A}-4$, length differences between the homologous chromosomes of pair no. 2, which is heterozygous for a knob in the long arm, could be detected, so that the two types of chromosomes are duly recorded in table 3 . On the other hand, no differences were found between the chromosomes of pair no. 7 which is heterozygous for a small knob at $7 L$.

The statistical comparison of these chromosome indices showed differences which are significant, at the 1 per cent level of probability between homologous chromosomes of Zapalote Chico and of Ceremonial maize. This finding

Table 3 Chromosome relative lengths expressed as percentages of chromosome of 10 of Zapalote Chico (stock 18) and Ceremonial (stock $371 \mathrm{~A}-4$ )

\begin{tabular}{|c|c|c|c|}
\hline Chromosome & $\begin{array}{l}\text { Zapalote Chico } \\
(n=22)\end{array}$ & $\begin{array}{l}\text { Ceremonial } \\
(n=18)\end{array}$ & $t$ \\
\hline \multirow{3}{*}{2} & $226 \cdot 63 \pm 16 \cdot 25$ & $198 \cdot 59 \pm 11 \cdot 60$ & $6 \cdot 15^{* * *}$ \\
\hline & $215 \cdot 04 \pm 16 \cdot 50$ & $K^{+} 17 \cdot 16 \pm 14 \cdot 61$ & $7 \cdot 60^{* *}$ \\
\hline & & $K^{-} 164 \cdot 52 \pm 11 \cdot 21$ & $11 \cdot 06^{* *}$ \\
\hline 3 & $204 \cdot 09 \pm 15 \cdot 44$ & $159 \cdot 52 \pm 10 \cdot 42$ & $10 \cdot 44^{* *}$ \\
\hline 4 & $196.92 \pm 15.69$ & $151 \cdot 39 \pm 7 \cdot 51$ & $12 \cdot 03^{* *}$ \\
\hline 5 & $182 \cdot 88 \pm 17 \cdot 95$ & $145 \cdot 12 \pm 8 \cdot 88$ & $8 \cdot 66^{* *}$ \\
\hline 6 & $158 \cdot 36 \pm 11 \cdot 58$ & $131 \cdot 14 \pm 9 \cdot 31$ & $8.06^{* *}$ \\
\hline 7 & $164 \cdot 46 \pm 10 \cdot 16$ & $122 \cdot 36 \pm 6 \cdot 80$ & $15 \cdot 03^{* *}$ \\
\hline 8 & $144 \cdot 47 \pm 11 \cdot 92$ & $120 \cdot 31 \pm 8 \cdot 08$ & $7 \cdot 32^{* *}$ \\
\hline 9 & $145 \cdot 14 \pm 9 \cdot 8$ & $108 \cdot 02 \pm 5 \cdot 04$ & $15 \cdot 44^{* *}$ \\
\hline 10 & $100 \cdot 00$ & $100 \cdot 00$ & \\
\hline
\end{tabular}

** Significant at the $1 \%$ level.

$n=$ Number of metaphases analysed.

$K^{+}$With knob.

$K^{-}$Without knob.

demonstrates that large and medium knobs of somatic chromosomes affect the lengths of somatic chromosome arms. 
Estimates of maize somatic chromosome lengths have been expressed as a percentage of the total complement length (Chen, 1969; Filion and Walden, 1973). However, the statistical comparison of the total complement length expressed in arbitrary units of the two stocks, analysed in the present study, revealed differences at the level of 1 per cent of probability. This finding demonstrates that the calculation of chromosome relative lengths, as a percentage of the haploid set, would not be a system suitable for the present work for comparing homologous heteromorphic chromosomes (table 4).

Table 4 Relative chromosome lengths of Zapalote Chico (stock 18) and Ceremonial (stock 371A-4) expressed as percentage of haploid set

\begin{tabular}{lcc}
\hline Chromosome & Zapalote Chico & Ceremonial \\
\hline 1 & $12 \cdot 91 \pm 0 \cdot 62$ & $14 \cdot 13 \pm 0 \cdot 64$ \\
2 & $12 \cdot 27 \pm 0 \cdot 47$ & $12 \cdot 14 \pm 0 \cdot 33^{*}$ \\
3 & $11 \cdot 72 \pm 0 \cdot 49$ & $11 \cdot 42 \pm 0.48$ \\
4 & $11 \cdot 3 \pm 0 \cdot 33$ & $10 \cdot 77 \pm 0 \cdot 30$ \\
5 & $10 \cdot 54 \pm 0 \cdot 65$ & $10 \cdot 24 \pm 0 \cdot 37$ \\
6 & $9 \cdot 32 \pm 0 \cdot 54$ & $9 \cdot 39 \pm 0 \cdot 47$ \\
7 & $9 \cdot 51 \pm 0 \cdot 74$ & $8 \cdot 55 \pm 0 \cdot 33$ \\
8 & $8 \cdot 44 \pm 0 \cdot 40$ & $8 \cdot 55 \pm 0 \cdot 46$ \\
9 & $8 \cdot 19 \pm 0 \cdot 36$ & $7 \cdot 69 \pm 0 \cdot 23$ \\
10 & $5 \cdot 82 \pm 0 \cdot 29$ & $7 \cdot 13 \pm 0 \cdot 33$ \\
\hline
\end{tabular}

* Without knobs.

Table 5 Arm ratios of chromosomes of Zapalote Chico (stock 18) and Ceremonial (stock 371 A-4)

\begin{tabular}{|c|c|c|c|}
\hline Chromosome & $\begin{array}{l}\text { Zapalote Chico } \\
(n=22)\end{array}$ & $\begin{array}{l}\text { Ceremonial } \\
(n=18)\end{array}$ & $t$ \\
\hline 1 & $1 \cdot 13 \pm 0 \cdot 11$ & $1 \cdot 19 \pm 0.07$ & $2 \cdot 0^{\text {n.s. }}$ \\
\hline \multirow[t]{2}{*}{2} & $1 \cdot 32 \pm 0 \cdot 10$ & $K^{+} 1.67 \pm 0.16$ & $8 \cdot 07^{* *}$ \\
\hline & & $K-1 \cdot 24 \pm 0 \cdot 13$ & $2 \cdot 20^{*}$ \\
\hline 3 & $1 \cdot 58 \pm 0.14$ & $1 \cdot 67 \pm 0 \cdot 18$ & $1 \cdot 78^{\text {n.s. }}$ \\
\hline 4 & $1 \cdot 33 \pm 0 \cdot 17$ & $1 \cdot 37 \pm 0 \cdot 11$ & $0.86^{\text {n.s. }}$ \\
\hline 5 & $1 \cdot 08 \pm 0.06$ & $1 \cdot 05 \pm 0.04$ & $1 \cdot 82^{\text {n.s. }}$ \\
\hline 6 & $1 \cdot 62 \pm 0 \cdot 18$ & $1 \cdot 60 \pm 0 \cdot 17$ & $0 \cdot 30^{\text {n.s. }}$ \\
\hline 7 & $1 \cdot 46 \pm 0 \cdot 15$ & $1 \cdot 81 \pm 0 \cdot 20$ & $6 \cdot 32^{* *}$ \\
\hline 8 & $2 \cdot 85 \pm 0.29$ & $2 \cdot 17 \pm 0 \cdot 15$ & $9 \cdot 55^{* *}$ \\
\hline 9 & $1.08 \pm 0.07$ & $1 \cdot 72 \pm 0 \cdot 14$ & $17 \cdot 67 * *$ \\
\hline 10 & $1.72 \pm 0.07$ & $1 \cdot 76 \pm 0 \cdot 20$ & $0 \cdot 66^{\mathrm{n} \cdot \mathrm{s}}$ \\
\hline
\end{tabular}

* Significant at the 5 per cent level.
** Significant at the 1 per cent level.

The values of chromosome arm ratios are shown in table 5. Significant differences at the 1 per cent level were observed between homologous chromosomes of the pairs no. 2, 7,8 and 9. This finding demonstrates that arm ratio values can be altered depending on the banding constitution of each chromosome.
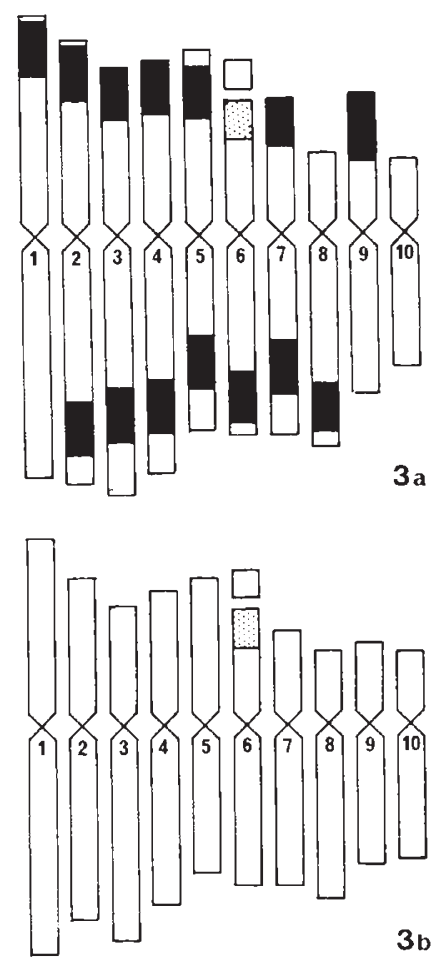

Figure 3 Diagrammatic representation of the C-banded karyotype of (a) Zapalote Chico (stock 18) and (b) of the basic maize somatic karyotype without bands obtained from Ceremonial maize data.

Idiograms representative of the somatic maize karyotype without bands and of stock 18 of Zapalote Chico are shown in fig. 3. Band widths have been estimated from differences between heteromorphic homologous arms. As can be seen in this idiogram, bands corresponding to knobs observed at pachytene, most of them interstitial, appear to be subtertminal or even terminal in somatic chromosomes due to their degree of contraction. In some cases and depending on the degree of condensation of metaphase chromosomes, the identification of some bands as terminal or subterminal may be rather difficult. This is the case of the short arm of chromosomes 1 and 2, in which the slightly subterminal appearance of the bands in their short arms can be better seen under the microscope in less condensed metaphases. Furthermore, the knob at $3 S$, which is clearly subterminal at pachytene, appears as terminal in somatic metaphases.

Further, it is also clear that there is a good correlation between band width and the degree of alteration of the length of a chromosome arm. The results presented in table 6 show significant differences between the homologous elements of pair 
Table 6 Relative chromosome lengths of chromosomes 2,6 and 8 with and without bands at their long arms (Ceremonial maize)

\begin{tabular}{llll}
\hline Chromosome & Band & Without Bands & $t$ \\
\hline 2 & $176 \cdot 0 \pm 15 \cdot 0(n=19)$ & $164 \cdot 0 \pm 0 \cdot 11(n=10)$ & $2 \cdot 89^{* *}$ \\
6 & $126 \cdot 78 \pm 11 \cdot 13(n=12)$ & $131 \cdot 14 \pm 9 \cdot 31(n=18)$ & $1 \cdot 16^{\text {n.s. }}$ \\
8 & $114 \cdot 34 \pm 8 \cdot 8(n=12)$ & $120 \cdot 31 \pm 8 \cdot 08(n=18)$ & $1 \cdot 91^{\text {n.s. }}$ \\
\hline
\end{tabular}

* Significant at the 1 per cent level.

$n=$ Number of metaphases analysed.

no. 2 of stock $371 \mathrm{~A}-4$, which is heterozygous for a large knob at $2 L$. Conversely, no significant differences were found between chromosomes of pairs no. 6 and 8 whether with or without bands corresponding to stocks 12 and $371 \mathrm{~A}-4$ respectively. It should be emphasised that the knobs at $6 L$ and $8 L$ are small.

The present data are consistent with evidence from the literature that heterochromatic blocks stained by $\mathrm{C}$-banding methods may represent additional material in the chromosomes (see Bennett et al., 1977; see also Flavell, 1980).

A good example of chromosome polymorphism involving additional material is that provided by the human $Y$ chromosome which has shown variability of its long arm among racial groups (Cohen et al., 1966), which is due to differences in the length of the distal heterochromatic segment, as visualised through quinacrine fluorescence (Bobrow et al., 1971) and Giemsa staining (Arrighi and Hsu, 1971).

In plants, many instances of polymorphism for telomeric and interstitial bands have been found in some genera. Correlations between the presence of large segments of heterochromatin and the increased length of chromosome arms, have been found in some investigations, as in species of the genus Secale (Bennett et al., 1977).

Although a larger DNA content does not correspond to a larger amount of heterochromatin, Bennett et al. (1977) observed a positive relationship between the proportion of the complement represented by terminal heterochromatin and the $4 C$ nuclear DNA content in some species of Secale. This provides the evidence in support of the notion that the increase in $4 C$ nuclear DNA content in species of Secale has involved a large increase in the amount of telomeric heterochromatin. Controversially, a comparison of the total lengths of the haploid complement with the $4 C$ DNA amount for nine Secale taxa, showed no significant relationship. However, this finding has been interpreted in the light of some evidence that metaphase chromosome volume can vary, according to the metabolic activity of the cell or to various environmental factors.

In this context, it is interesting to emphasize the positive relationship that we have found between the values of the diploid complement length, measured in Feulgen stained metaphases and the frequency of knobs, in the maize stocks analysed in this study. Further, the use of a chromosome index expressed as a percentage of chromosome 10, has made possible the clear demonstration that the morphology of maize somatic chromosomes can be drastically modified according to the band patterns.

Very few references have been found in the literature, with respect to polymorphism of maize somatic chromosomes. Filion and Walden (1973) mentioned that variations of arm ratios could be observed in metaphase chromosomes of different maize stocks, but no evidence was shown of correlation between arm lengths and band widths.

The C-banded chromosome diagram presented in fig. 3(a), although representative only of the stock of Zapalote Chico used in this study, can be considered illustrative of band positions in maize somatic chromosomes and may be useful in the future standardization of maize somatic cytogenetics.

Acknowledgements One of the authors (M.L.R.A.P.) wishes to thank Dr Almiro Blumenschein of the Department of Genetics ESALQ, University of S. Paulo, Brazil for the valuable supply of seeds from which the stocks used in the above study were derived. She is also very grateful to Dr N. A. Vello of the same Department for help and advice in the statistical analysis.

This work was supported by grants from the Conselho Nacional de Desenvolvimento Cientifico e Tecnologico (P16 111/ $\mathrm{CNP}_{\mathrm{q}} /$ Finep).

\section{REFERENCES}

AGUIAR-PERECIN, DE, M. R. L. 1984. C-banding in Maize: 1. Banding patterns. Caryologia (in press).

ARRIGHI, F. AND HSU, T. C. 1971. Localisation of heterochromatin in human chromosomes. Cytogenetics, 10, 81-86. 
BENNETT, M. D., GUSTAFSON, J. P. AND SMITH, J. B. 1977. Variation in nuclear DNA in the genus Secale. Chromosoma, 61, 149-176.

BOBROW, M., PEARSON, P. L., PIKE, M. C. AND EL ALFI, O. S. 1971. Length variation in the quinacrine-binding segment of the human $Y$ chromosome of different sizes. Cytogenetics, 10, 190.

BRIEGER, F. G., GURGEL, J. T. A., PATERNIANI, E., BLUMENSCHEIN, A. AND ALLEONI, M. R. 1958. Races of maize in Brazil and other eastern South Ariserican countries. Nat. Acad. Sci. Nat. Res. Council, Washington, D.C. Publ. 593. CHEN, C. C. 1969. The somatic chromosomes of maize. Can. J. Genet. Cytol., 11, 752-754.

COHEN, M. M., SHAW, M. W. ANI MACCluer, J.W. 1966. Racial differences in the length of the human $Y$ chromosome. Cytogenetics, 5, 34-52.

FILION, W. G. AND WALDEN, D. B. 1973. Karyotype analysis The detection of chromosomal alterations in the somatic karyotype of Zea mays L. Chromosoma, 41, 183-194.

FLAVELL, R. 1980. The molecular characterisation and organisation of plant chromosomal DNA sequences. Ann. Rev. Plant Physiol., 31, 569-596.

GREILHUBER, J. AND SPETA, F. 1976. C-banded karyotypes in the Scilla hohenakeri group. S. persica and Puschkinia (Liliaceae) Plant Syst. Evol., 126, 149-188.
HADLACZKY, GY. AND KÁLMÁN, L. 1975. Discrimination of homologous chromosomes of maize with Giemsa staining. Heredity, 35, 371-374.

MCCLINTOCK, B. 1978. Significance of chromosome constitution in tracing the origin and migration of races of maize in the Americas. In Maize Breeding and Genetics. Walder, D. B. (ed.) Wiley, New York, pp. 159-184.

NEUFFER, M. G., JONES, L. AND ZUBER, M. S. 1968. The mutants of maize. Crop. Science Society of America, Madison, 74p.

PARIS CONFERENCE. 1971. Standardization in Human Cytogenetics. Birth defects: Original articles series VIII: 7, 1972. The National Foundation, New York.

SACHAN, J. K. S. AND TANAKA, R. 1977. Variation in pattern of C-banding in Zea chromosomes. Nucleus, 20, 61-62.

RHOADES, M. M. 1950. Meiosis in maize. J. Hered., 41, 58-67. STEEL, R. G. D. AND TORIE, S. M. 1960. Principles and procedures of statistics. McGraw-Hill, New York, $481 \mathrm{p}$.

VOSA, C. G. AND AGUIAR, M. L. R. DE. 1972. New techniques for knob detection in mitotic chromosomes in maize and teosinte. Maize Genet. Coop. Newsl., 46, 165-167.

WARD, E. J. 1980. Banding patterns in maize mitotic chromosomes. Can. J. Genet. Cytol., 22, 61-67. 